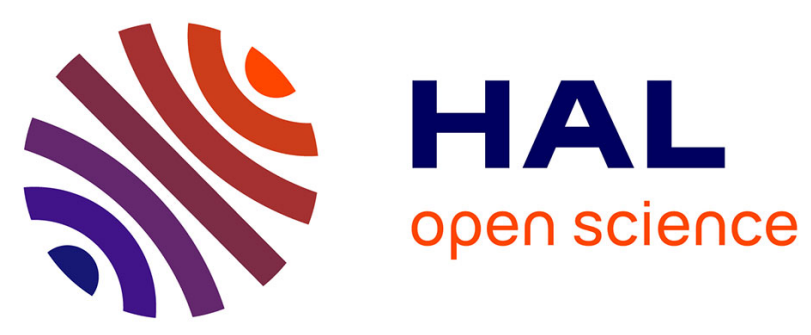

\title{
HIGH-K THIN FILMS AS DIELECTRIC TRANSDUCERS FOR FLEXURAL M/NEMS RESONATORS
}

\author{
Cécile Fuinel, Khadim Daffé, Adrian Laborde, Olivier Thomas, Laurent \\ Mazenq, Liviu Nicu, Thierry Leichle, Bernard Legrand
}

\section{To cite this version:}

Cécile Fuinel, Khadim Daffé, Adrian Laborde, Olivier Thomas, Laurent Mazenq, et al.. HIGH-K THIN FILMS AS DIELECTRIC TRANSDUCERS FOR FLEXURAL M/NEMS RESONATORS. The 29th IEEE International Conference on Micro Electro Mechanical Systems (MEMS 2016), IEEE, Jan 2016, Shanghai, China. 10.1109/MEMSYS.2016.7421850 . hal-01279717

\section{HAL Id: hal-01279717 https://hal.science/hal-01279717}

Submitted on 26 Feb 2016

HAL is a multi-disciplinary open access archive for the deposit and dissemination of scientific research documents, whether they are published or not. The documents may come from teaching and research institutions in France or abroad, or from public or private research centers.
L'archive ouverte pluridisciplinaire HAL, est destinée au dépôt et à la diffusion de documents scientifiques de niveau recherche, publiés ou non, émanant des établissements d'enseignement et de recherche français ou étrangers, des laboratoires publics ou privés. 


\title{
HIGH-K THIN FILMS AS DIELECTRIC TRANSDUCERS FOR FLEXURAL M/NEMS RESONATORS
}

\author{
Cécile Fuinel ${ }^{1}$, Khadim Daffe ${ }^{l}$, Adrian Laborde ${ }^{1}$, Olivier Thomas ${ }^{2}$, Laurent Mazenq ${ }^{l}$, Liviu Nicu ${ }^{1}$, \\ Thierry Leichlé ${ }^{1}$, and Bernard Legrand ${ }^{l}$ \\ ${ }^{1}$ CNRS, LAAS, 7 avenue du colonel Roche, F-31400 Toulouse, FRANCE \\ Univ de Toulouse, LAAS, F-31400 Toulouse, FRANCE \\ ${ }^{2}$ Arts et Métiers ParisTech LSIS UMR CNRS 7296, 8 bd. Louis XIV F-59046 Lille, FRANCE
}

\begin{abstract}
We show that a nanometer-thick high-K material can be used as an electromechanical transducer to actuate the flexural mode of micro/nanoresonators. In this study, a $15 \mathrm{~nm}$ silicon nitride layer is employed on top of $320 \mathrm{~nm}$ thick silicon beams. The devices, smaller by 2 orders of magnitude than in previous studies [1], are successfully driven into vibration at resonance frequencies greater than $1 \mathrm{MHz}$, nanometer amplitudes, and quality factors greater than 2,000 in vacuum. We also deduce the transduction efficiency from a thermomechanical displacement noise calibration. This work paves the way for efficient electromechanical transduction scheme at the nanoscale, which would be further strengthened by the use of high-K dielectric materials obtained by atomic layer deposition.
\end{abstract}

\section{CONTEXT}

Electromechanical transduction is a fundamental constituent of M/NEMS devices, especially in actuators, physical sensors and resonators. Efficiency, reliability and integration with fabrication technology are major challenges that have to be faced to exploit the transduction principles. In particular, as the device dimensions decrease down to the NEMS scale, the electromechanical transductions meet stringent difficulties. For example, the capacitive transduction suffers from low efficiencies or failures by stiction due to narrow airgaps; the piezoelectric transduction is impeded by material quality and drastic decrease of its electromechanical coupling when the piezoelectric film thickness is reduced below $100 \mathrm{~nm}$ [2]. In this context, the dielectric transduction appears as an attractive option: it was demonstrated as an effective transduction scheme at millimetric dimensions [1]. High-quality high-K materials available in very thin films $(<10 \mathrm{~nm})$, using atomic layer deposition (ALD) techniques fully compatible with silicon microtechnologies, make it promising for micro and nano-electromechanical devices.
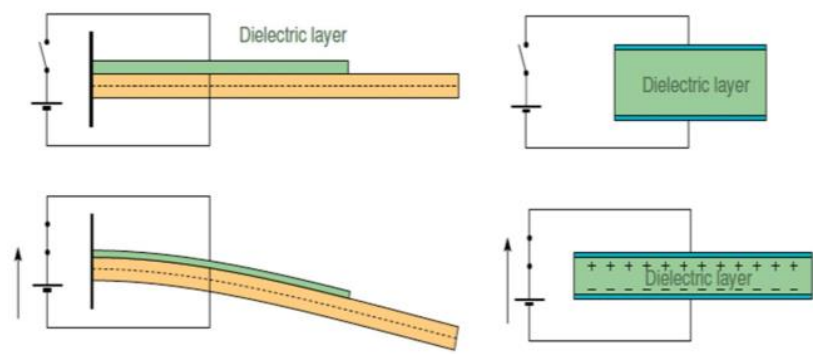

Figure 1: Schematic principle of the dielectric actuation.
Actuation is obtained when applying a voltage across the dielectric film, which causes an electrostatic pressure that is translated into an in-plane stress by the elastic laws. If placed on top of a mechanical beam, a flexural displacement is then observed, as schematically shown in Figure 1.

\section{EXPERIMENTAL RESULTS}

Device fabrication

Cantilever beam and clamped-clamped (CC) beam resonators are designed as described in Figure 2. Fabrication technology relies on UV photolithography and standard silicon micromachining. It starts from a boron doped silicon-on-insulator wafer (top silicon layer and buried oxide thicknesses are respectively $320 \mathrm{~nm}$ and $1,000 \mathrm{~nm}$ ). Trenches are then etched leading to air bridges along the signal paths to reduce extra parasitic capacitance to ground. A low-stress silicon nitride, is employed for the proof-of-concept as high-K dielectric material $\left(\varepsilon_{\mathrm{r}} \approx 8, \mathrm{v}_{\mathrm{d}}=0.23\right)$ for actuation. A $15 \mathrm{~nm}$-thick layer of the dielectric material is deposited on top of the silicon by low-pressure chemical vapor deposition (LPCVD), followed by a $20 \mathrm{~nm}$-thick sputtered chromium layer, which acts as the electrode to apply the voltage across the dielectric film. Cantilever and CC beams are then patterned and etched through the material stack by a combination of chemical and reactive ion etching. Devices' dimensions are $w=5 \mu \mathrm{m}, e=320 \mathrm{~nm}$, and $L=18 \mu \mathrm{m}$ for cantilevers and $L=30 \mu \mathrm{m}$ for CC beams. Finally, a $250 \mathrm{~nm}$-thick sputtered gold layer is added for interconnects and contact pads before releasing the structures using a chemical etching of the buried oxide based on a HF solution. Figures $3 \mathrm{a}$ and $3 \mathrm{~b}$ show the details of fabricated devices.

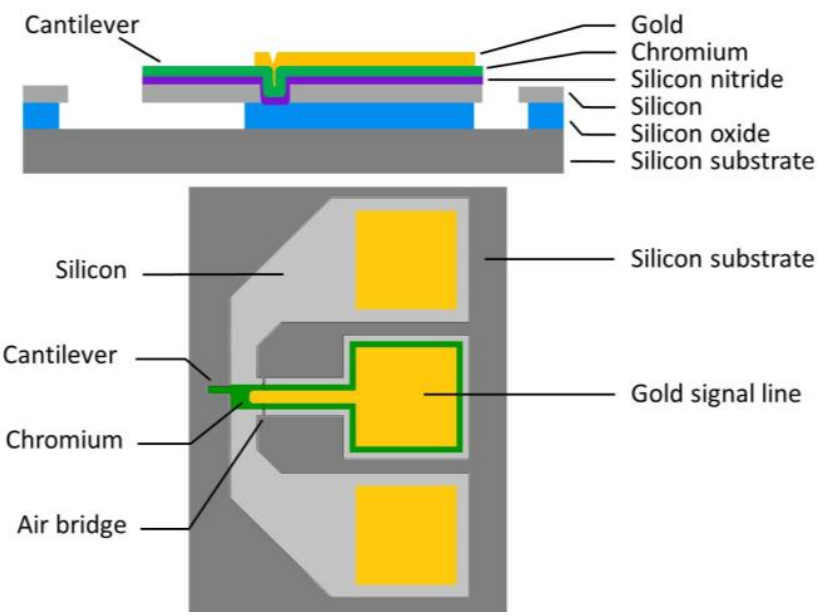

Figure 2 Schematic cross-section (top), and top view (bottom) of a micro-cantilever device. 

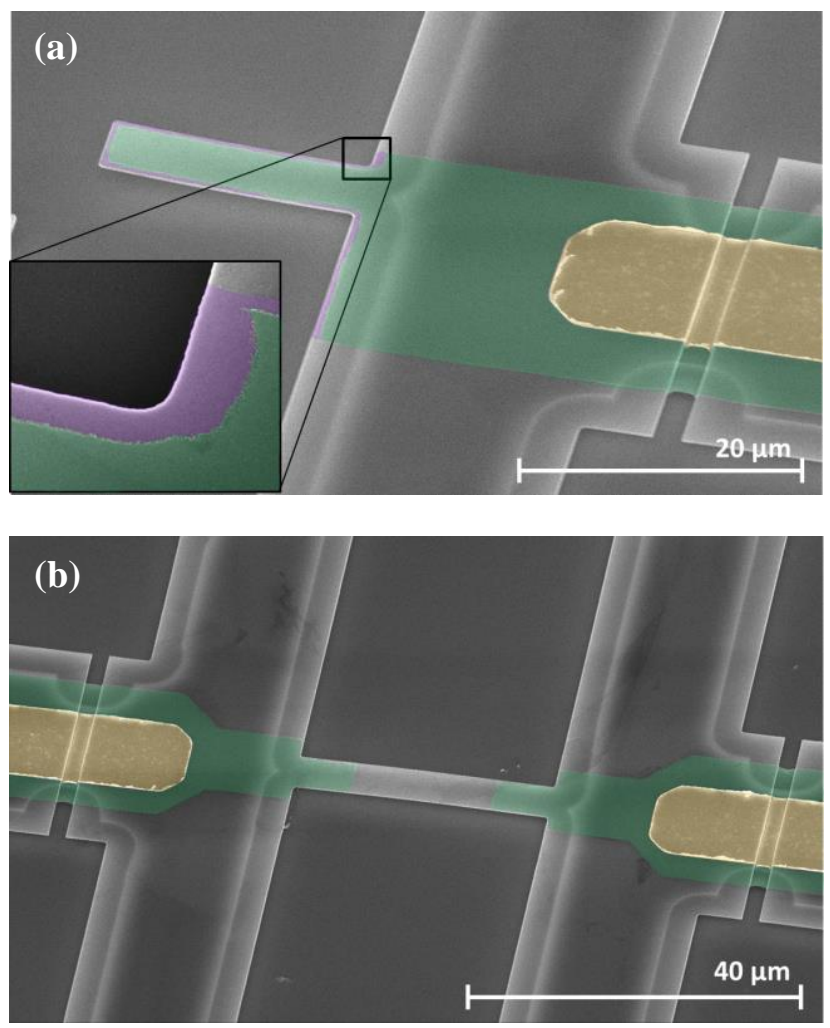

Figure 3: Scanning electron microscope images of fabricated devices. (a) The cantilever. Inset: close view of the junction of the cantilever with the support at the anchor location. (b) The CC beam with two dielectric transducers located close to the beam anchors.

\section{Electrical actuation}

The devices were driven into oscillation in vacuum using a DC + AC voltage applied across the dielectric film. Vibration resonance frequencies of the devices were measured using Fabry-Perot interferometry. A laser beam is reflected both on the vibrating resonator and on the substrate. The resulting interferometry signal, modulated by the vibration, is then detected by a photodiode, and its frequency response is analyzed as shown in Figure 4.

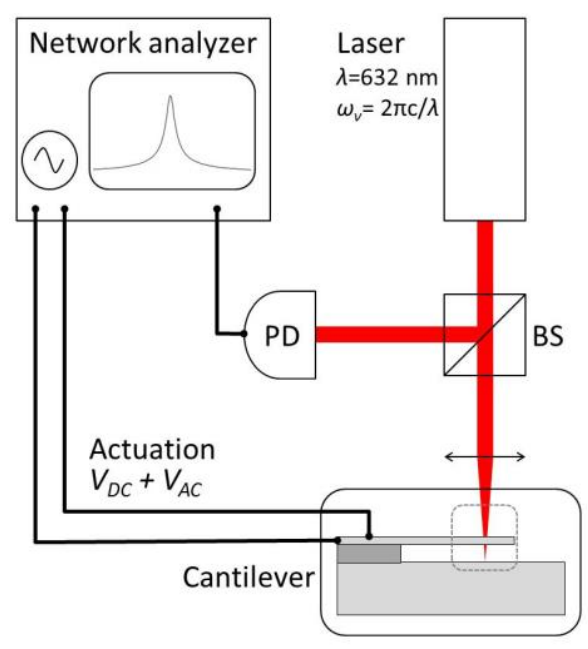

Figure 4: Resonance frequency measurement set-up. The laser reflection from the device is directed to the photodiode (PD) by the beam splitter $(B S)$ to be analyzed.

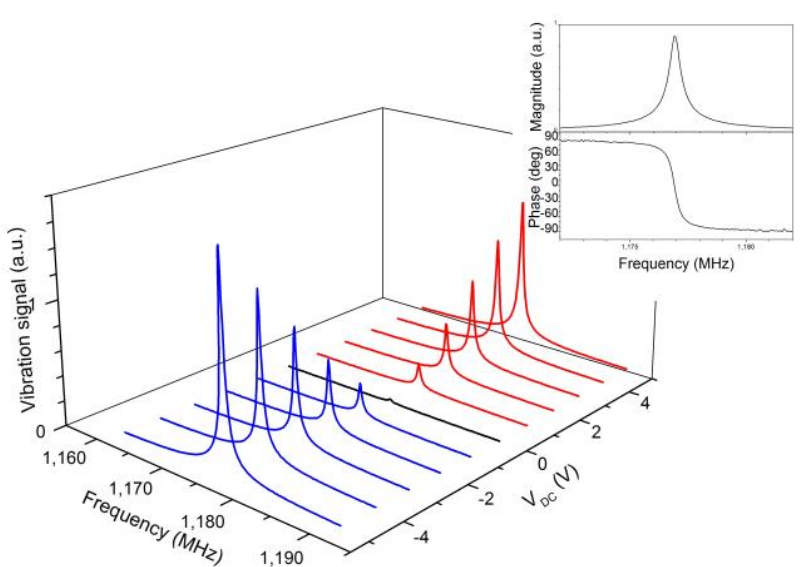

Figure 5: Measurement by optical interferometry of the magnitude signal of the cantilever device close to resonance for $V_{D C}$ values ranging from $-5 \mathrm{~V}$ to $+5 \mathrm{~V}$, showing a linear dependence between the vibration amplitude and $V_{D C}$. Inset: Measurement when driven by $V_{D C}=2 \mathrm{~V}$ and $V_{A C}=15 \mathrm{mV}$ applied to the chromium top electrode. Resonance frequency and $Q$ factor are $1.1768 \mathrm{MHz}$ and 2,050 in vacuum, respectively.

The $5 \mu \mathrm{m} \times 18 \mu \mathrm{m}$ cantilever beam resonator is actuated in vacuum $\left(P=7.10^{-2} \mathrm{mBar}\right)$, for actuation voltage $V_{A C}=15 \mathrm{mV}$ and $V_{D C}$ ranging from $-5 \mathrm{~V}$ to $5 \mathrm{~V}$. The measured spectra are shown in Figure 5. The figure inset shows magnitude and phase. The measured resonance frequency is $f_{\text {res }}=1.1768 \mathrm{MHz}$, which is in a good agreement with the one obtained by finite element modeling (FEM) taking into account the stack of materials and anchor geometry $\left(f_{\text {res_FEM }}=1.1773 \mathrm{MHz}\right.$, cf. Fig. 6). Quality factor is $Q=2,050$. As the principle of operation of the dielectric actuation is based on the electrostatic pressure applied to the dielectric film, a linear dependence of the vibration amplitude versus the bias voltage $V_{D C}$ is expected. This was verified as displayed in Figure 5.

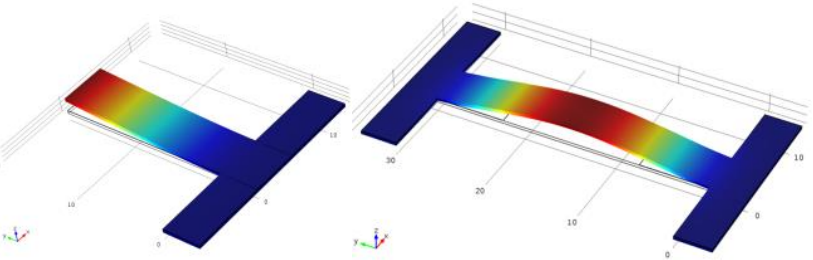

Figure 6: FEM modelling using COMSOL software of a $5 \mu \mathrm{m} \times 18 \mu \mathrm{m}$ cantilever beam resonator (left) and a $5 \mu \mathrm{m} \times 30 \mu \mathrm{m} C \mathrm{C}$ beam devices (right) taking into account the silicon nitride and chromium top layers and buried oxide over etching at the anchor location. $1^{\text {st }}$ mode resonance frequency is calculated to be $1.1773 \mathrm{MHz}$ for the cantilever and $2.6551 \mathrm{MHz}$ for the CC beam. 


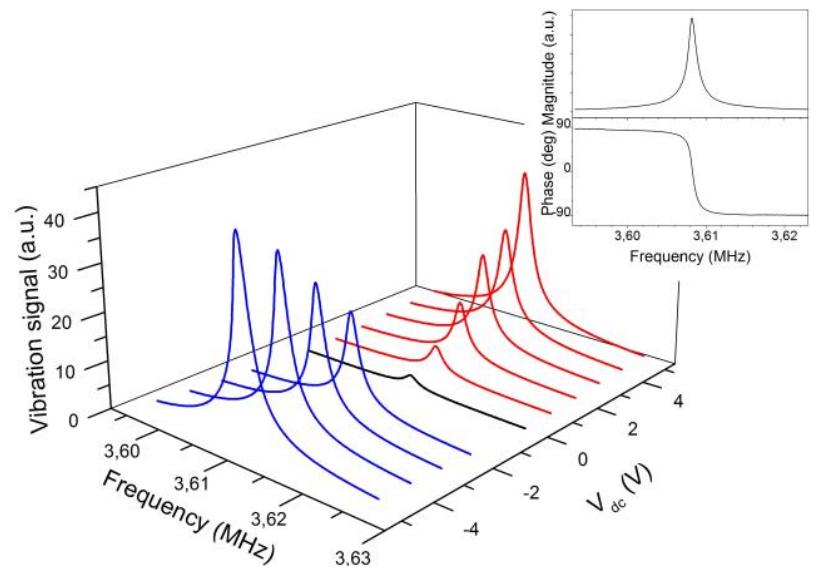

Figure 7: Measurement of the magnitude signal of the CC beam device close to resonance for $V_{D C}$ values ranging from $-5 \mathrm{~V}$ to $+5 \mathrm{~V}$, showing a linear dependence between the vibration amplitude and $V_{D C}$. Inset: Measurement when driven by $V_{D C}=2 \mathrm{~V}$ and $V_{A C}=250 \mathrm{mV}$ applied to the chromium top electrode. Resonance frequency and $Q$ factor are $3.61123 \mathrm{MHz}$ and 3,400 in vacuum, respectively.

The $5 \mu \mathrm{m} \times 30 \mu \mathrm{m}$ CC beam is actuated similarly at $P=4.4 \mathrm{mBar}$. This higher pressure was chosen for the experiments to avoid non-linear phenomenon which appear at high quality factors for this geometry, the Qfactor reaching values greater than 20,000 in the $10^{-2}$ $\mathrm{mBar}$ pressure range. The actuation voltage is $V_{A C}=250 \mathrm{mV}$ superimposed to $V_{D C}$ ranging from $-5 \mathrm{~V}$ to $+5 \mathrm{~V}$. The Figure 7 inset shows both magnitude and phase. The measured resonance frequency is $f_{\text {res }}=3.6076$ $\mathrm{MHz}$, which is about $1 \mathrm{MHz}$ higher than expected by FEM modeling $\left(f_{\text {res_FEM }}=2.6551 \mathrm{MHz}\right.$, cf. Fig. 6). The discrepancy can be explained by the tensile stress induced by the stack of nitride and chromium layers. This tensile stress cannot be relaxed in such a $\mathrm{CC}$ beam configuration as it is at the free end of the cantilever beam. As a consequence, the beam effective stiffness is increased as well as its resonance frequency. Quality factor is $Q=3,400$. Linear dependence of the vibration amplitude versus the bias $V_{D C}$ was also verified as displayed in Figure 7.

\section{Vibration displacement calibration}

Transduction efficiency is a key parameter to assess the performance of the actuation scheme. It can be deduced from the calibrated value of the vibration amplitude at resonance, knowing the driving voltage $V_{A C}$, the effective stiffness $K_{\text {eff }}$ and the Q-factor. In the following, the measurements are calibrated thanks to the observation of the thermomechanical noise. The Figure 8 a shows the thermomechanical displacement noise spectrum of the cantilever beam. The measurement is obtained at the same pressure as mentioned above. It comes from the Langevin force that the thermomechanical amplitude $A_{\text {thermo }}$ is $2 \mathrm{pm} . \mathrm{Hz}^{-0.5}$, assuming a cantilever spring constant $K_{\text {eff }}=1.1 \mathrm{~N} / \mathrm{m}$ obtained from analytical calculations.

Vibration amplitudes are then calibrated [2,3], showing that in forced regime, nanometer displacements are obtained. Furthermore, the efficiency of the device transducer $\eta$ is deduced from these experimental data knowing the values of $K_{\text {eff }}$ and $Q$. Its value is $145 \mathrm{pN} / \mathrm{V}$ for $V_{D C}=2 \mathrm{~V}$, which is in a good agreement with the theoretical value of $168 \mathrm{pN} / \mathrm{V}$, calculated from an analytical formula derived from the approach of References [4] and [5]:

$$
\eta=\kappa \frac{e w}{L t} \frac{v_{d}}{\left(1-v_{d}\right)} \epsilon_{0} \epsilon_{r} V_{D C}
$$

where $\boldsymbol{\kappa}$ is a factor depending on the mode shape and on the dielectric transducer length and location along the beam, $t$ is the dielectric film thickness, $\boldsymbol{v}_{\boldsymbol{d}}$ its Poisson ratio and $\boldsymbol{\epsilon}_{\boldsymbol{r}}$ its relative permittivity. $\boldsymbol{\kappa}=0.68$ for the $1^{\text {st }}$ mode of a cantilever beam fully covered by the stack of the dielectric and electrode materials, and $\boldsymbol{\kappa}=1.54$ for the $1^{\text {st }}$ mode of a $\mathrm{CC}$ beam with a transducer length equal to 0.225 of the beam length $L$. Using the same approach, the transduction efficiency is obtained in the case of the CC beam. Experimental measurements are shown in Figure $8 \mathrm{~b}$, leading to $\boldsymbol{\eta}=112 \mathrm{pN} / \mathrm{V}$ for $V_{D C}=2 \mathrm{~V}$.
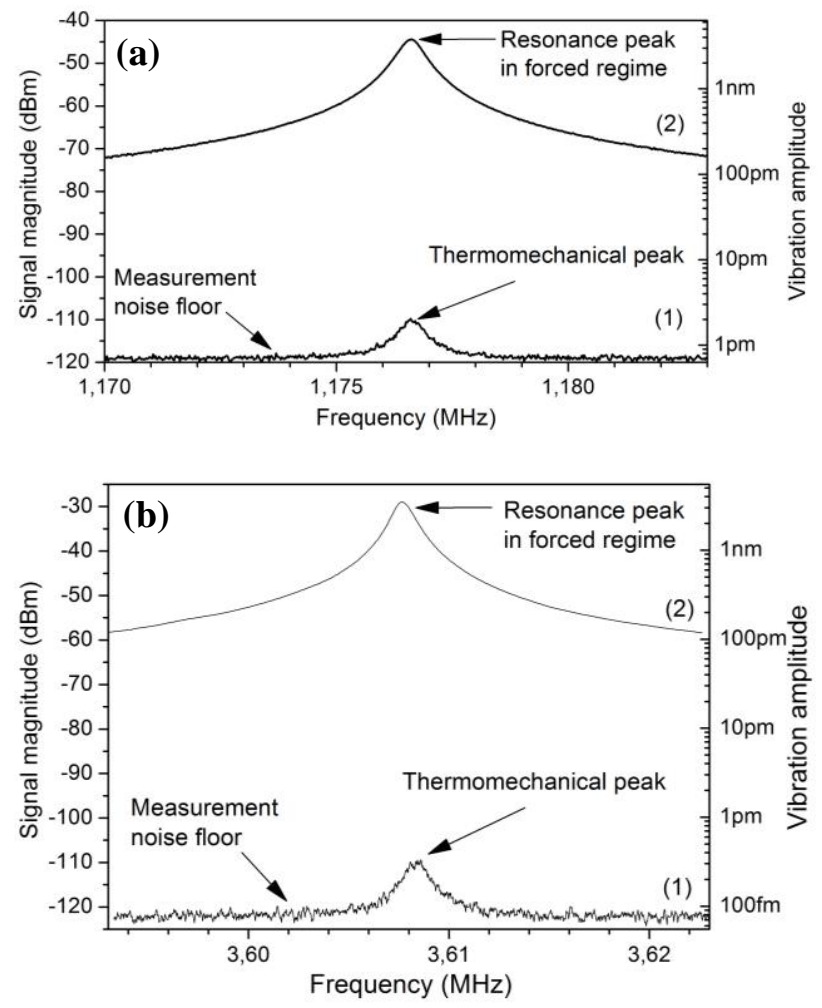

Figure 8: (a) Vibration amplitude of the device of Fig. $3 a$ when (1) no actuation signal is applied, showing the thermomechanical displacement noise of the cantilever measured with a $1-\mathrm{Hz}$ bandwidth, and (2) in forced regime with $V_{D C}=2 \mathrm{~V}$ and $V_{A C}=15 \mathrm{mV}$. (b) Vibration amplitude of the device of Fig. $3 b$ when (1) no actuation signal is applied, showing the thermomechanical displacement noise of the CC beam measured with a $1-\mathrm{Hz}$ bandwidth, and (2) in forced regime with $V_{D C}=2 \mathrm{~V}$ and $V_{A C}=250 \mathrm{mV}$. Knowing that the thermomechanical peak amplitude is given by $A_{\text {thermo }}=\left(2 k_{B} T Q / \pi f_{\text {res }} K_{\text {eff }}\right)^{1 / 2}$, measurement of the displacement is calibrated as indicated by the right axis. 
The following tables summarize the key parameters and results for the cantilever beam in Table 1 and the $\mathrm{CC}$ beam in Table 2.

Table 1: Table summarizing the parameters of the cantilever device and the dielectric transducer. Calculations take into account the buried oxide over etching at the anchor location.

\begin{tabular}{l|l|l|l}
\multicolumn{2}{c|}{ Cantilever parameters } & \multicolumn{2}{c}{ Transducer parameters } \\
\hline Length & $18 \mathrm{um}$ & Material & Si nitride \\
\hline Width & $5 \mathrm{um}$ & Thickness & $15 \mathrm{~nm}$ \\
\hline Si thickness & $320 \mathrm{~nm}$ & Permittivity & $\varepsilon_{\mathrm{r}} \approx 8$ \\
\hline Eff. stiffness & $1.1 \mathrm{~N} / \mathrm{m}$ & $\begin{array}{l}\text { Transducer } \\
\text { efficiency theoret. }\end{array}$ & $\begin{array}{l}168 \mathrm{pN} / \mathrm{V} \\
\text { at } \mathrm{V}_{\mathrm{DC}}=2 \mathrm{~V}\end{array}$ \\
\hline$f_{\text {res }}$ FEM & $1.1773 \mathrm{MHz}$ & $\begin{array}{l}\text { Transducer } \\
\text { efficiency experi. }\end{array}$ & $\begin{array}{l}145 \mathrm{pN} / \mathrm{V} \\
\text { at } \mathrm{V}_{\mathrm{DC}}=2 \mathrm{~V}\end{array}$ \\
\hline$f_{\text {ree }}$ experim. & $1.1768 \mathrm{MHz}$ & $\begin{array}{l}\text { Vibration ampl. } \\
\text { for } \mathrm{V}_{\mathrm{DC}}=2 \mathrm{~V} \\
\mathrm{~V}_{\mathrm{AC}}=15 \mathrm{mV}\end{array}$ & $3.8 \mathrm{~nm}$ \\
\hline $\begin{array}{l}\text { Q factor } \\
\begin{array}{l}\text { Themomech. } \\
\text { amplitude }\end{array}\end{array}$ & 2,050 & $2 \mathrm{pm} . \mathrm{Hz}^{-0.5}$ &
\end{tabular}

Table 2: Table summarizing the parameters of the CC beam device and the dielectric transducer. Calculations take into account the buried oxide over etching at the anchor location and the tensile stress of the beam except for $f_{\text {res }} F E M$.

\begin{tabular}{l|l|l|l}
\multicolumn{2}{c|}{ CC beam parameters } & \multicolumn{2}{c}{ Transducer parameters } \\
\hline Length & $30 \mathrm{um}$ & Material & Si nitride \\
\hline Width & $5 \mathrm{um}$ & Thickness & $15 \mathrm{~nm}$ \\
\hline Si thickness & $320 \mathrm{~nm}$ & Permittivity & $\varepsilon_{\mathrm{r}} \approx 8$ \\
\hline Eff. stiffness & $27,8 \mathrm{~N} / \mathrm{m}$ & $\begin{array}{l}\text { Transducer } \\
\text { efficiency theoret. }\end{array}$ & $\begin{array}{l}223 \mathrm{pN} / \mathrm{V} \\
\text { at } \mathrm{V}_{\mathrm{DC}}=2 \mathrm{~V}\end{array}$ \\
\hline$f_{\text {res }} \mathrm{FEM}$ & $2.6551 \mathrm{MHz}$ & $\begin{array}{l}\text { Transducer } \\
\text { efficiency experi. }\end{array}$ & $\begin{array}{l}112 \mathrm{pN} / \mathrm{V} \\
\text { at } \mathrm{V}_{\mathrm{DC}}=2 \mathrm{~V}\end{array}$ \\
\hline$f_{\text {res }}$ experim. & $3.6076 \mathrm{MHz}$ & $\begin{array}{l}\text { Vibration ampl. } \\
\text { for } \mathrm{V}_{\mathrm{DC}}=2 \mathrm{~V} \\
\mathrm{~V}_{\mathrm{AC}}=250 \mathrm{mV}\end{array}$ & $3.2 \mathrm{~nm}$ \\
\hline $\begin{array}{l}\text { Q factor } \\
\begin{array}{l}\text { Themomech. } \\
\text { amplitude }\end{array}\end{array}$ & 3,400 & $0.3 \mathrm{pm} . \mathrm{Hz}-{ }^{-0.5}$ &
\end{tabular}

\section{CONCLUSION}

Dielectric actuation was successfully demonstrated for flexural devices with nanometer scale material thicknesses and the transduction efficiency was obtained from calibrated measurements using the thermomechanical noise displacement spectra. Results are in a good agreement with theoretical calculations, especially concerning the transduction efficiency. This transduction principle, being based on electrostatic/capacitive effects, is reciprocal and can also be used for sensing purposes. Moreover, it paves the way for electromechanical mixing actuation and detection schemes [6], allowing parasitic crosstalk rejection and down-conversion of the motional current to enhance the detection sensitivity of NEMS devices.

\section{ACKNOWLEDGEMENTS}

We acknowledge Renatech Network and in particular the LAAS clean room staff for its constant support.

\section{REFERENCES}

[1] S. Bouwstra, F.R. Blom, T.S.J. Lammerink, H. Yntema, P. Schrap, J.H.J. Fluitman, M. Elwenspoek, "Excitation and detection of vibrations of micromechanical structures using a dielectric thin film", Sensors and Actuators, 17, 219-223, 1989.

[2] D. Dezest, O. Thomas, F. Mathieu, L. Mazenq, C. Soyer, J. Costecalde, D. Remiens, J.F. Deü, L. Nicu, "Wafer-scale fabrication of self-actuated piezoelectric nanoelectromechanical resonators based on lead zirconate titanate (PZT)", Journal of Micromechanics and Microengieering, 25, 3, 035002, 2015.

[3] R.B. Karabalin, M.H. Matheny, X.L. Feng, E. Defaÿ, G. Le Rhun, C. Marcoux, S. Hentz, P. Andreucci, M.L. Roukes, Applied Physics Letters, 95, 103111, 2009.

[4] D.L. DeVoe, "Piezoelectric thin film micromechanical beam resonators", Sensors and Actuators A, 88, 263-272, 2001.

[5] O. Thomas, B. Legrand, C. Fuinel, "Optimization of length and thickness of smart transduction layers on beam structures for control and $\mathrm{m} / \mathrm{nems}$ applications", in Preoceedings of SMASIS 2015 (ASME 2015 Conference on Smart Materials Adaptive Structures and Intelligent Systems), paper 8857, Colorado Springs, USA, September 2015.

[6] H.B. Peng, C.W. Chang, S. Aloni, T.D. Yuzvinsky, A. Zettl, Physical Review Letters, 97, 087203, 2006.

\section{CONTACT}

Cécile Fuinel

Tel.: +33561337953

E-mail: cecile.fuinel@laas.fr

Khadim Daffé is now with IEMN-CNRS, Villeneuve d'Ascq, France 